\title{
Open-Label, Pilot Study of the Safety and Clinical Effects of Rituximab in Patients with Rheumatoid Arthritis-Associated Interstitial Pneumonia
}

\author{
Eric L. Matteson ${ }^{1,2}$, Tim Bongartz ${ }^{1}$, Jay H. Ryu ${ }^{3}$, Cynthia S. Crowson ${ }^{2}$, Thomas E. Hartman ${ }^{4}$, \\ Paul F. Dellaripa ${ }^{5}$ \\ ${ }^{1}$ Division of Rheumatology, Rochester, USA; ${ }^{2}$ Department of Health Sciences Research, Rochester, USA; ${ }^{3}$ Division of Pulmonary \\ and Critical Care Medicine, Rochester, USA; ${ }^{4}$ Department of Radiology, Mayo Clinic College of Medicine, Rochester, USA; \\ ${ }^{5}$ Division of Rheumatology, Brigham and Womens Hospital, Boston, USA. \\ Email: matteson.eric@mayo.edu
}

Received May $24^{\text {th }}, 2012$; revised June $28^{\text {th }}, 2012$; accepted July $9^{\text {th }}, 2012$

\begin{abstract}
Objective: To investigate the clinical effect of rituximab (RTX) in the management of progressive rheumatoid arthritis related interstitial lung disease (RA-ILD). Methods: A total of 10 patients with progressive RA-ILD were enrolled into this 48-week, open-label treatment study. Treatment was with RTX at $1000 \mathrm{mg}$ at day 1 , day 15 , and again at weeks 24 and 26, with concomitant methotrexate therapy. Results: The study included 4 men and 6 women. Of 7 evaluable patients at week 48 , the diffusing capacity to carbon monoxide had worsened by at least $15 \%$ in 1 patient, and was stable in 4 patients, and increased by $>15 \%$ of baseline value in 2 patients. The forced vital capacity declined by at least $10 \%$ in 1 patient, was stable in 4 patients, and increased by at least $10 \%$ in 2 patients. High resolution computed tomography of the chest showed improvement in 1 patient, and was unchanged in 5. Three patients were withdrawn, one who had an infusion reaction at week 0 , one at week 5 who was hospitalized for congestive heart failure at week 5 and who later died at week 32 of complications following a traumatic hip fracture, and one died at week 6 of possible pneumonia. Conclusions: In this pilot study of 10 patients with RA-ILD treated with RTX, measures of lung disease remained stable in the majority of study completers. Further research is needed to clarify whether this treatment has a role in management of RA-ILD.
\end{abstract}

Keywords: Rheumatoid Arthritis; Interstitial Pneumonitis; Rituximab

\section{Introduction}

Pulmonary involvement is common in patients with rheumatoid arthritis (RA), and clinically overt interstitial lung disease (ILD) is prevalent in about $8 \%$ of patients with early RA and $19 \%$ of patients with a longer disease duration [1-3]. The 10 year incidence rate of symptomatic pulmonary fibrosis has been described as high as $6 \%$ in patients with RA $[2,3]$. The presence of ILD in RA has a significant adverse impact on mortality $[2,4]$.

To date, no clinical trial has assessed the efficacy of any therapy in RA-ILD. Therapeutic strategies are entirely based on therapeutic recommendations in idiopathic interstitial pneumonias (IIP) [5-7]. In view of some histologic differences between IIPs and their counterparts in RA, there might be important features which could impact on treatment efficacy and prognosis [3]. At the same time, assumptions about effectiveness of diease modifying drugs (DMARDs) on pulmonary disease de- rived from their impact on joint disease should be treated with caution.

The pathogenesis of RA-ILD is unknown. Other disease related features and smoking are risk factors, and a number of immunologic, cellular and humoral abnormalities have been described in RA-ILD [2,8-10]. Formation of B-cell follicles and germinal centers and the presence of circulating antibodies to lung proteins have been detected in IIP [8]. There may be a significant increase in B-cell numbers in RA-ILD compared to normal lung tissue and IIPs, and there are dense B-cell follicles in the two most common histologic subtypes of RA-ILD, nonspecific interstitial pneumonia (NSIP) and usual interstitial pneumonia (UIP) [9].

These observations provide a rationale for a potential efficacy of B-cell ablative therapies in RA-ILD. The use of a monoclonal antibody directed against CD20, a B-cell surface marker, has already proven effectiveness in the treatment of RA joint disease, but the effect on lung dis- 
ease has not been evaluated [11]. This study was performed to gain a preliminary assessment of the safety and clinical effect of rituximab, an established therapy for RA, in patients with moderate to severe clinically overt and progressive RA-ILD.

\section{Methods}

\subsection{Patients}

The study population consisted of 4 male and 6 female outpatients with RA associated UIP or NSIP, ages 43 to 80 years. All patients met the revised 1987 American College of Rheumatology classification criteria for RA [12]. The study was approved by the Institutional Review Boards of the Mayo Clinic and the Brigham and Women's Hospital, and registered with Clinicaltrials gov. as NCT00578565.

Diagnosis of progressive RA-ILD of UIP or NSIP subtype was based on the following criteria: 1) Clinical symptoms consistent with ILD with onset between 3 months and 36 months prior to screening; 2) Progressive ILD as demonstrated by any one of the following within the past year: $>10 \%$ decrease in forced vital capacity (FVC), increasing infiltrates on chest radiograph or high resolution computed tomography (HRCT), or worsening dyspnea at rest or on exertion; 3) Diagnosis of UIP or NSIP by either surgical lung biopsy or HRCT showing definite or probable UIP or NSIP; 4) Abnormal pulmonary function results (reduced FVC or decreased diffusing capacity to carbon monoxide (DLco) or impaired gas exchange at rest or with exercise and 5) Insidious onset of otherwise unexplained dyspnea or exertion and bibasilar, inspiratory crackles on auscultation. Only patients with an FVC $>50 \%$ of predicted value at screening and DLco $>30 \%$ of predicted value at screening were enrolled. No patient had lung biopsy.

Patients were excluded who had clinical features suggesting infection, neoplasm, sarcoidosis, ILD other than UIP or NSIP, other collagen vascular disease, or exposure to known fibrogenic drugs or environmental factors. Other exclusions included FEV1/FVC ratio $<0.6$ at screening (pre or post-bronchodilator), residual volume $>$ $120 \%$ predicted at screening, history of unstable or deteriorating cardiac or neurologic disease, abnormal neurologic examination, history of tuberculosis or test positive for human immunodeficiency virus or hepatitis B or $\mathrm{C}$, pregnancy or lactation, creatinine $>1.5 \mathrm{x}$ upper limit of normal, and IgG and IgM levels below lower limit of normal. Treatment exclusions included previous exposure to cyclophosphamide, cyclosporine, interferon gamma or beta, anti-tumor necrosis factor therapy, anti-IL1 therapy or with endothelin receptor blockers within the last 8 weeks. Patients who had previously received rituximab or experimental therapy for RA were also ex- cluded. No change of DMARD treatment within the last 3 months prior to trial enrollment was allowed.

\subsection{Treatment}

Rituximab $1000 \mathrm{mg}$ was administered by intravenous (i.v.) infusion on days 1 and 15 with repeat dosing at weeks 24 and 26. All subjects received $100 \mathrm{mg}$ of i.v. methylprednisolone as premedication. Continuation of DMARD treatment and oral prednisone established at least 3 months prior to inclusion at a stable dose was allowed. The use of systemic corticosteroid therapy was permitted up to a dose of $15 \mathrm{mg} /$ day during the study. Administration of higher doses of corticosteroids at the discretion of the patient's primary physician was permitted for a period not to exceed two weeks in the event of a rapid clinical deterioration in clinical status.

\subsection{Clinical Assessments}

Measures of pulmonary efficacy and function including the FVC, DLco and St. George's respiratory questionnaire were obtained at screening and at weeks 12, 24 and 48 [13]. HRCT was performed at screening and weeks 24 and 48. The HRCTs were independently assessed by a radiologist expert in pulmonary radiology for ILD related changes using a standard scoring system for ground glass attenuation, reticulation, honeycombing, decreased attenuation, centrilobular nodules, other nodules, emphysema and consolidation on a 0 to 4 scale: $0=$ no involvement, 1 $=1 \%-25 \%$ involvement, $2=26 \%-50 \%$ involvement, 3 $=51 \%-75 \%$ involvement, $4=76 \%-100 \%$ involvement [8]. Health-related quality of life and function were assessed with patient questionnaires, including the Medical Outcomes Study Short Form 36 item instrument (SF-36), the Health Assessment Questionnaire (HAQ), Clinical Disease Activity Index (CDAI) and the 28 joint disease activity score (DAS28).

\subsection{Biomarkers}

CD19 counts were measured at baseline and 12, 24, 36, and 48 weeks.

\subsection{Analytic Approach}

The primary endpoint of the study was the safety of rituximab therapy in RA-ILD as assessed through patient history, physical exams and laboratory parameters at 48 weeks. Secondary endpoints were assessment of progression-free survival at 48 weeks. Based on consensus recommendations, progression was defined as: decrease of baseline $\mathrm{FVC} \geq 10 \%$ (and at least $\geq 200$-ml change), $15 \%$ decrease in single-breath DLco or death from progressive lung [7]. Other outcome parameters included radiographic 
progression over 48 weeks on HRCT, the St. George respiratory questionnaire, quality of life measures Medical Outcomes Study SF-36, HAQ, DAS28 and CDAI.

\section{Results}

The study included 4 men and 6 women with mean age 64.7 years (range 43 to 80 ) who had RA (mean duration 13.8 years; range 0.4 to 44 ) and ILD (mean duration 3.2 years; range 0.0 to 7.5 ). Rheumatoid factor and/or anti CCP antibody was present in 7/10 patients (pts). UIP was present in 4 patients, and NSIP in 6. Medications at enrollment included prednisone ( $8 \mathrm{pts}$ ), methotrexate (4 pts), and sulfasalazine (1 pt).

Function and activity measures over the course of the study are contained in Table 1. Baseline pulmonary function included mean $\mathrm{FVC}$ 68\% (min: 47\%, max: $89 \%$ ), mean DLco $47.6 \%$ (min: $28 \%$, max: $73 \%$ ), mean FEV1/FVC ratio 86.5 (min: 68.8, max: 101), mean St. George's score 54.7 (min: 4.0, $\max 92.5 ; 0=$ best, and
100 = worst), Mean SF-36 physical component score was 23.2 (min: 11.4, max: 43.5), and the mean mental component score was 47.8 (min: 32.4, max: 57.3).

Changes in the function and activity measures are contained in Table 1. By week 48, the DLco had worsened by at least $15 \%$ (at least $\geq 3 \mathrm{ml} / \mathrm{min} / \mathrm{mm} \mathrm{Hg}$ ) in 1 patient, was stable in 4 patients, and increased by $>15 \%$ of baseline in 2 patients. The FVC declined by at least $10 \%$ (and at least $\geq 200 \mathrm{ml}$ ) in 1 patient, was stable in 4 patients, and increased by at least $10 \%$ in 2 patients. There was no clinically meaningful change in the St. George's respiratory score. Serial HRCT examinations revealed improvement in 1 patient, and worsening in another patient, with no changes noted on HRCT for the other 5 patients assessed at week 48 (Table 2).

Among the 7 patients who reached week 48, 4 had NSIP and 3 had UIP. Of the 3 UIP patents, 1 improved by FVC and DLco and the other 2 remained stable by DLco, FVC and HRCT. Of the 4 NSIP patients, 1 worsened

Table 1. Function and activity measures in patients with rheumatoid arthritis related intersitial pneumonia treated with rituximab.

\begin{tabular}{|c|c|c|c|c|c|c|c|}
\hline Measure & $\begin{array}{l}\text { Baseline } \\
\mathrm{N}=10\end{array}$ & $\begin{array}{l}\text { Week } 12 \\
\mathrm{~N}=7\end{array}$ & $\begin{array}{l}\text { Week } 12 \text { change } \\
\text { from baseline }\end{array}$ & $\begin{array}{l}\text { Week } 24 \\
\mathrm{~N}=7\end{array}$ & $\begin{array}{l}\text { Week } 24 \text { change } \\
\text { from baseline }\end{array}$ & $\begin{array}{c}\text { Week } 48 \\
\mathrm{~N}=7\end{array}$ & $\begin{array}{l}\text { Week } 48 \text { change } \\
\text { from baseline }\end{array}$ \\
\hline FVC, $\%$ & $68(47,89)$ & $80.5(67,100)$ & $\begin{array}{c}6.5 \% \\
(0 \%, 15 \%)\end{array}$ & $76.3(51,104)$ & $\begin{array}{c}1.5 \% \\
(-11 \%, 20 \%)\end{array}$ & $75.3(50,102)$ & $\begin{array}{c}2.4 \% \\
(-12 \%, 17 \%)\end{array}$ \\
\hline DLco, $\%$ & $47.6(28,73)$ & $52.4(35,70)$ & $\begin{array}{c}-0.5 \% \\
(-18 \%, 13 \%)\end{array}$ & $53.2(33,63)$ & $\begin{array}{c}15.3 \% \\
(-7 \%, 54 \%)\end{array}$ & $52.0(30,75)$ & $\begin{array}{c}11.6 \% \\
(-22 \%, 47 \%)\end{array}$ \\
\hline FEV1/FVC & $86.5(68.8,101)$ & $88.4(79.1,109)$ & $\begin{array}{c}2.4 \% \\
(-5 \%, 8 \%)\end{array}$ & $91.5(75.9,115)$ & $\begin{array}{c}3.4 \% \\
(-4 \%, 14 \%)\end{array}$ & $88.1(77,109)$ & $\begin{array}{c}0 \% \\
(-10 \%, 8 \%)\end{array}$ \\
\hline $\begin{array}{l}\text { St. George's } \\
\text { score }\end{array}$ & $54.7(4.0,92.5)$ & $50.6(2.3,85.5)$ & $\begin{array}{c}4.9 \% \\
(-43 \%, 62 \%)\end{array}$ & $49.5(5.0,81.9)$ & $\begin{array}{c}14.4 \% \\
(-17 \%, 107 \%)\end{array}$ & $51.5(23.3,68.5)$ & $\begin{array}{c}81.1 \% \\
(-33 \%, 478 \%)\end{array}$ \\
\hline $\begin{array}{l}\text { SF-36 physical } \\
\text { component score }\end{array}$ & $23.2(11.4,43.5)$ & $26.7(13.4,42.7)$ & $\begin{array}{c}8.1 \% \\
(-33 \%, 48 \%)\end{array}$ & $23.9(17.5,40.6)$ & $\begin{array}{c}21.0 \% \\
(-1 \%, 54 \%)\end{array}$ & $28.0(19.6,34.4)$ & $\begin{array}{c}37.0 \% \\
(-31 \%, 116 \%)\end{array}$ \\
\hline $\begin{array}{l}\text { SF-36 mental } \\
\text { component score }\end{array}$ & $47.8(32.4,57.3)$ & $56.9(47.7,62.6)$ & $\begin{array}{c}7.3 \% \\
(-2 \%, 20 \%)\end{array}$ & $50.0(43.1,64.3)$ & $\begin{array}{c}-4.3 \% \\
(-21 \%, 13 \%)\end{array}$ & $54.5(39.0,65.1)$ & $\begin{array}{c}9.9 \% \\
(-10 \%, 62 \%)\end{array}$ \\
\hline DAS28 ESR & $5.5(2.2,7.3)$ & - & - & $4.6(3.2,6.8)$ & $\begin{array}{c}-21.3 \% \\
(-42 \%, 9 \%)\end{array}$ & $3.3(2.5,4.4)$ & $\begin{array}{c}-31.8 \% \\
(-62 \%, 24 \%)\end{array}$ \\
\hline CDAI & $32.5(2.9,54.7)$ & $-9.3, \mathrm{~N}=1$ & $-66 \%, N=1$ & $18.5(2.1,59.4)$ & $\begin{array}{c}-12.4 \% \\
(-80 \%, 121 \%)\end{array}$ & $10.4(2.5,24.6)$ & $\begin{array}{c}-38.5 \% \\
(-92 \%, 59 \%)\end{array}$ \\
\hline HAQ & $1.2(0.25,2.375)$ & $0.8(0.125,1.625)$ & $\begin{array}{c}50.7 \% \\
(-67 \%, 200 \%)\end{array}$ & $1.0(0.375,1.5)$ & $\begin{array}{c}49.1 \% \\
(-21 \%, 250 \%)\end{array}$ & $1.0(0.25,1.5)$ & $\begin{array}{c}85.9 \% \\
(-80 \%, 300 \%)\end{array}$ \\
\hline
\end{tabular}

Values in table are means (minimum, maximum); $\mathrm{N}=$ Number, $\mathrm{FVC}=$ Forced vital capacity; DLco = Diffusing capacity of carbon monoxide; $\mathrm{SF}-36=\mathrm{Medical}$ Outcomes Study Short Form 36; DAS = Disease activity score; ESR = Erythrocyte sedimentation rate; CDAI = Clinical disease activity index; HAQ = Health assessment questionnaire. 
Table 2. Finding on high resolution computed tomography of the lungs.

\begin{tabular}{|c|c|c|c|c|}
\hline & $\begin{array}{l}\text { Prior to base- } \\
\text { line }(\mathrm{N}=8)\end{array}$ & $\begin{array}{l}\text { Baseline } \\
(\mathrm{N}=10)\end{array}$ & $\begin{array}{c}\text { Week 24 } \\
(\mathrm{N}=7)\end{array}$ & $\begin{array}{r}\text { Week 48 } \\
(\mathrm{N}=7)\end{array}$ \\
\hline Nodular opacities & 4 & 3 & 1 & 1 \\
\hline Size $\leq 5 \mathrm{~mm}$ & 3 & 1 & 1 & 1 \\
\hline $6-10 \mathrm{~mm}$ & 0 & 1 & 0 & 0 \\
\hline$>10 \mathrm{~mm}$ & 1 & 1 & 0 & 0 \\
\hline Extent $<10 \%$ & 3 & 2 & 0 & 0 \\
\hline $10 \%-40 \%$ & 1 & 0 & 0 & 0 \\
\hline$>40 \%$ & 0 & 1 & 1 & 1 \\
\hline Irregular linear opacities & 7 & 9 & 7 & 7 \\
\hline Extent $<10 \%$ & 4 & 4 & 2 & 2 \\
\hline $10 \%-40 \%$ & 3 & 5 & 5 & 5 \\
\hline$>40 \%$ & 0 & 0 & 0 & 0 \\
\hline Interlobular septa thickening & 0 & 1 & 1 & 0 \\
\hline Ground glass infiltrates & 5 & 9 & 7 & 6 \\
\hline Extent away from fibrosis $0 \%$ & 1 & 5 & 4 & 4 \\
\hline$<10 \%$ & 2 & 2 & 2 & 1 \\
\hline $10 \%-40 \%$ & 2 & 2 & 1 & 1 \\
\hline$>40 \%$ & 0 & 0 & 0 & 0 \\
\hline Extent in areas of fibrosis $0 \%$ & 0 & 3 & 2 & 1 \\
\hline$<10 \%$ & 4 & 3 & 3 & 3 \\
\hline $10 \%-40 \%$ & 1 & 3 & 2 & 2 \\
\hline$>40 \%$ & 0 & 0 & 0 & 0 \\
\hline Consolidation & 0 & 1 & 2 & 1 \\
\hline Emphysema & 2 & 3 & 2 & 3 \\
\hline Extent $<10 \%$ & 2 & 2 & 1 & 2 \\
\hline $10 \%-40 \%$ & 0 & 1 & 1 & 1 \\
\hline$>40 \%$ & 0 & 0 & 0 & 0 \\
\hline Honeycombing & 2 & 5 & 3 & 3 \\
\hline Extent $<10 \%$ & 2 & 5 & 3 & 3 \\
\hline $10 \%-40 \%$ & 0 & 0 & 0 & 0 \\
\hline$>40 \%$ & 0 & 0 & 0 & 0 \\
\hline
\end{tabular}

Table 3. Individual patient pulmonary data at week 48 for 10 patients with rheumatoid arthritis related interstitial pneumonia disease treated with rituximab.

\begin{tabular}{ccccccccccc}
\hline Parameter & Pt 1 NSIP & Pt 2 NSIP & Pt 3 UIP & Pt 4 UIP & Pt 5 UIP & Pt 6 NSIP & Pt 7 NSIP & Pt 8 NSIP & Pt 9 NSIP & Pt 10 UIP \\
\hline DLco & S & WD & S & S & D & D & S & W & I & I \\
FVC & S & WD & S & S & D & D & I & S & W & I \\
HRCT & S & WD & S & S & D & D & S & I & W & S \\
\hline
\end{tabular}

$\mathrm{I}=$ Improved; $\mathrm{S}=$ Stable; $\mathrm{W}=$ Worsened; $\mathrm{D}=$ Death, and $\mathrm{WD}=$ Withdrew from study. For DLco, worsening was defined as decrease of at least $15 \%$ and improvement was defined as increase of at least $15 \%$. For FVC, worsening was defined as decrease of at least $10 \%$ and improvement was defined as increase of at least $10 \%$. Pt $=$ Patient; FVC $=$ Forced vital capacity; DLco $=$ Diffusing capacity of carbon monoxide; NSIP $=$ Nonspecific interstitial pneumonitis; UIP $=$ Usual interstitial pneumonitis. 
by FVC and HRCT but improved by DLco and another worsened by DLco, 1 improved by FVC and 1 remained stable by DLco, FVC and HRCT (Table 3).

Although not formally assessed, clinical joint disease activity parameters including the mean DAS28 and CDAI were improved in surviving patients by weeks 24 and 48. Mean Medical Outcomes Study Short Form 36 and Health Assessment Questionnaire scores were globally unchanged by weeks 24 and 48 . As expected, CD19 counts dropped dramatically, from normal to zero or near 0 in most patients by week 24 , and continued to be low at week 48 (data not shown).

Three patients did not complete the 48 weeks study. One patient had an infusion reaction with the first infusion, and withdrew from the study. One patient was hospitalized for congestive heart failure at week 5 , unlikely to be related to study drug, and later died at week 32 of complications following a traumatic hip fracture. Another patient died at week 6 of possible pneumonia and adult respiratory distress syndrome; a causative organism was not recovered.

\section{Discussion}

The overall research objective of this study was to examine the course of patients with progressive RA-ILD treated with rituximab by evaluation of safety and progression-free survival at 48 weeks following initial treatment. Facing the current lack of clinical trial data in RAILD, we expected also to gain important information on the usefulness of potential study endpoints, the magnitude of response that can be expected in a clinical trial of RA-ILD, and potential difficulties that can be associated with a certain trial design and the overall feasibility of a full-scale randomized controlled trial.

In this pilot study of 10 patients with progressive RA-ILD who were treated with conventional doses of rituximab used in the management of RA, there were significant adverse events including two deaths. Given the small number of patients, the relationship of these events to treatment vs. underlying disease is unclear. Of the 7 patients who reached week 48 , only 1 could be said to have improved, while 1 worsened and 5 were stable. Although the numbers of patients in the study was small, it could not be determined whether patients with NSIP or UIP were more likely to respond.

As an aim of the study was to determine if use of this therapy would result in improvement, it could be concluded that there was not a signal for clinical efficacy of this treatment for RA IP. However, 5 patients remained stable, which may be of significance since worsening of parameters of lung disease was a requirement for enrollment into the trial. Nevertheless, it cannot be disregarded that three patients did not complete the study, including two patients who died. Of these noncompleters, the death following the hip fracture was unlikely related to the study drug, and it is uncertain whether the death at week 6 due to possible pneumonia and respiratory distress syndrome was related to the study drug. Pulmonary toxicity to rituximab has been reported principally in patients receiving it for malignancy indications, with isolated cases reported in rheumatoid arthritis [14,15]. In general, the most common presentation is acute/subacute hypoxemic organizing pneumonia starting 2 weeks after the last infusion (often around the 4th cycle when given weekly). Adult respiratory distress syndrome has also been reported, usually within hours after the first infusion [16]. In one survey of 45 patients with presumed rituximab pulmonary injury, 8 patients died [16].

Clearly, further research is needed to clarify whether this treatment has a role in management of RA-ILD in less advanced disease, or in specific histopathologic patterns of disease. This research will necessarily include the development of improved sets of outcomes for evaluation of patients with RA-ILD [14].

\section{Author Contributions}

All authors were involved in drafting the article or revising it critically for important intellectual content, and all authors approved the final version to be published. Dr. Matteson had full access to all of the data in the study and takes responsibility for the integrity of the data and the accuracy of the data analysis. Study conception and design: Bongartz, Matteson, Ryu. Acquisition of data: Matteson, Bongartz, Dellarippa. Analysis and interpretation of data: Matteson, Bongartz, Dellaripa, Hartman, Ryu, Crowson.

\section{Funding}

Funding for this project was provided by the Mayo Clinic Foundation, and was supported by NIH/NCRR CTSA Grant Number UL1 RR024150. Its contents are solely the responsibility of the authors and do not necessarily represent the official views of the NIH. The study drug was provided without cost by Genentech, Inc.

\section{Acknowledgements}

We would like to especially thank our study coordinators Ms. Jane Jaquith and Jade Cumberbatch as well as the staff of the Mayo Clinic Clinical and the Brigham and Women's Hospital Research Units for their time and dedication in facilitating the conduct of this study.

\section{REFERENCES}

[1] C. Turesson, W. M. O'Fallon, C. S. Crowson, S. E. 
Gabriel and E. L. Matteson, "Extra-Articular Disease Manifestations in Rheumatoid Arthritis: Incidence Trends and Risk Factors over 46 Years," Annals of the Rheumatic Diseases, Vol. 62, No. 8, 2003, pp. 722-727. doi:10.1136/ard.62.8.722

[2] T. Bongartz, C. Nannini, Y. F. Medina-Velasquez, S. J. Achenbach, C. S. Crowson, J. H. Ryu, R. Vassallo, S. E. Gabriel and E. L. Matteson, "Incidence and Mortality of Interstitial Lung Disease in Rheumatoid Arthritis," Arthritis \& Rheumatism, Vol. 62, No. 5, 2010, pp. 15831591. doi:10.1002/art.27405

[3] C. Nannini, J. H. Ryu and E. L. Matteson, "Lung Disease in Rheumatoid Arthritis," Current Opinion in Rheumatology, Vol. 20, No. 3, 2008, pp. 340-346.

[4] S. V. Kocheril, B. E. Appleton, E. C. Somers, E. A. Kazerooni, K. R. Flaherty, F. J. Martinez, et al., "Comparison of Disease Progression and Mortality of Connective Tissue Disease-Related Interstitial Lung Disease and Idiopathic Interstitial Pneumonia," Arthritis \& Rheumatism, Vol. 53, No. 2, 2005, pp. 549-557.

[5] K. Phillips, K. R. Flaherty, E. L. Matteson, T. Bongartz, J. Bathon, K. K. Brown and P. F. Dellaripa, "Interstitial Lung Disease in Rheumatoid Arthritis," Current Rheumatology Reviews, Vol. 6, No. 2, 2010, pp. 120-126.

[6] C. Turesson and E. L. Matteson, "Extraarticular Features of Rheumatoid Arthritis and Systemic Involvement," In: M. C. Hochberg, A. J. Silman, J. S. Smolen, M. E. Weinblatt and M. H. Weisman, Eds., Rheumatology, 5th Edition, Mosby, Philadelphia, 2011, pp. 839-847.

[7] G. Raghu, H. R. Collard, J. J. Egan, F. J. Martinez, J. Behr, K. K. Brown, et al., "An Official ATS/ERS/JRS/ ALAT Statement: Idiopathic Pulmonary Fibrosis: Evidence-Based Guidelines For Diagnosis and Management," American Journal of Respiratory and Critical Care Medicine, Vol. 183, No. 7, 2011, pp. 788-782.

[8] W. A. Wallace, S. E. Howie, A. S. Krajewski and D. Lamb, "The Immunological Architecture of B-Lymphocyte Aggregates in Cryptogenic Fibrosing Alveolitis," Journal of Pathology, Vol. 178, No. 3, 1996, pp. 323-329.

[9] S. R. Atkins, C. Turesson, J. L. Myers, H. D. Tazelaar, J. H. Ryu, E. L. Matteson, et al., "Morphologic and Quantitative Assessment of CD20+ B Cell Infiltrates in Rheumatoid Arthritis-Associated Nonspecific Interstitial Pneumonia and Usual Interstitial Pneumonia," Arthritis \&
Rheumatism, Vol. 54, No. 2, 2006, pp. 6635-6641.

[10] C. Turesson, E. L. Matteson, T. V. Colby, Z. Vuk-Pavlovic, R. Vassallo, C. M. Weyand, et al., "Increased CD4+ T cell Infiltrates in Rheumatoid Arthritis-Associated Interstitial Pneumonitis Compared with Idiopathic Interstitial Pneumonitis," Arthritis \& Rheumatism, Vol. 52, No. 1, 2005, pp. 73-79.

[11] P. Emery, R.Fleischmann, A. Filiowicz-Sosnowska, J. Schechtman, L. Szczepanski, A. Kavanaugh, et al., "The Efficacy and Safety of Rituximab in Patients with Active Rheumatoid Arthritis Despite Methotrexate Treatment: Results of a Phase IIB Randomized, Double-Blind, Placebo-Controlled, Dose-Ranging Trial," Arthritis \& Rheumatism, Vol. 54, No. 5, 2006, pp. 1390-1400. doi: $10.1002 /$ art. 21778

[12] F. C. Arnett, S. M. Edworthy, D. A. Bloch, D. J. McShane, J. F. Fries, N. S. Cooper, et al., "The American Rheumatism Association 1987 Revised Criteria for the Classification of Rheumatoid Arthritis," Arthritis \& Rheumatism, Vol. 31, No. 3, 1988, pp. 315-324. doi:10.1002/art.1780310302

[13] P. W. Jones, “The St George's Respiratory Questionnaire," Respiratory Medicine, Vol. 85, No. B, 1991, pp. 25-31.

[14] L. A. Saketkoo, E. L. Matteson, K. K. Brown, J. R. Seibold, V. Strand, P. Dellaripa, K. Flaherty, D. Huscher, D. Khanna, C. V. Oddis, K. Phillips, D. Pittrow, A. Wells, C. Denton, O. Distler, A. Fischer, O. Kowal-Bielecka, S. Mittoo and J. Swigris, "Developing Disease Activity and Response Criteria in Connective Tissue Disease-Related Interstitial Lung Disease," The Journal of Rheumatology, Vol. 38, No. 7, 2011, pp. 1514-1518. doi:10.3899/jrheum.110281

[15] A. V. Hadjinicolaou, M. K. Nisar, H. Parfrey, E. R. Chilvers and A. J. K. Östör, "Non-Infectious Pulmonary Toxicity of Rituximab: A Systematic Review," Rheumatology, Vol. 51, No. 4, 2012, pp. 653-662. doi:10.1093/rheumatology/ker290

[16] H. Liote, F. Liote, B. Seroussi, C. Mayaud and J. Cadranel, "Rituximab-Induced Lung Disease: A Systematic Literature Review," European Respiratory Journal, Vol. 35, No. 3, 2010, pp. 681-687. doi:10.1183/09031936.00080209 